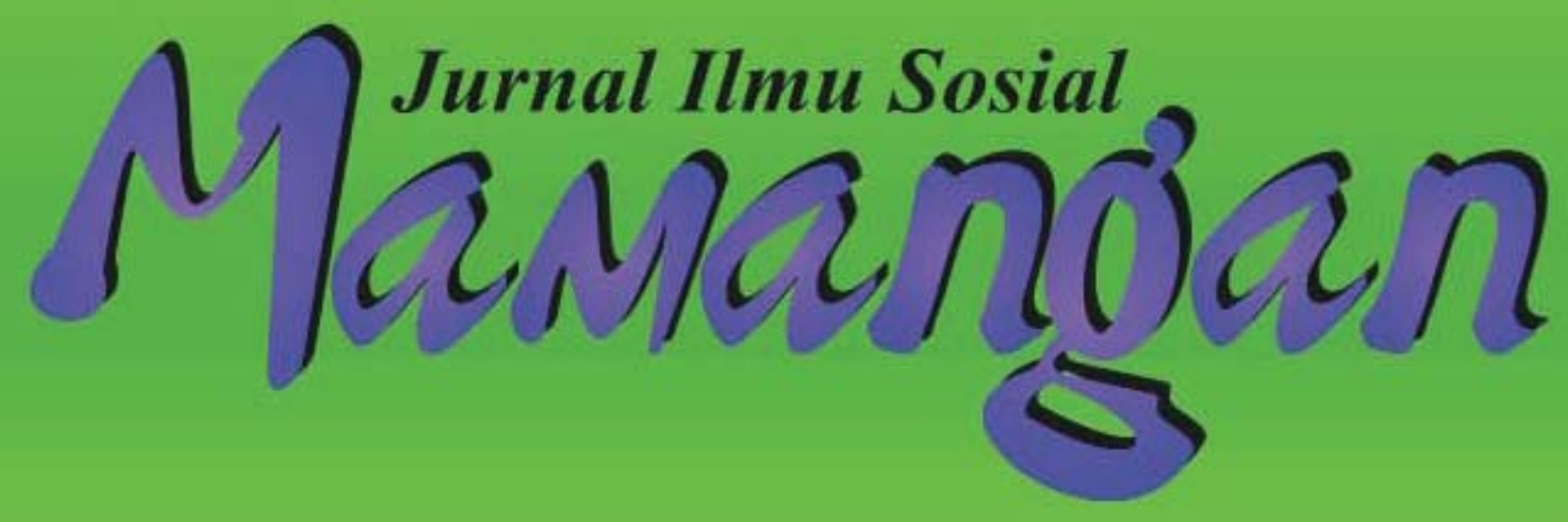

Beberapa Hipotesis Tentang Eksklusi Sosial di Indonesia Robert M.Z. Lawang

Dapatkah Indonesia Bebas Dari Kutukan Kolonial?

Refleksi Kritis Atas MP3EI

Noer Fauzi Rachman \& Dian Yanuardy

Rontoknya Dominasi Negara di Tambang Batu Bara Ombilin Sawahlunto

Zaiyardam Zubir \& Zulqayyim

Protes Korban Bencana; Studi Konflik Penanggulangan Bencana di Pasar Raya Padang

Firdaus

Peran Perempuan dalam Resolusi Konflik Rehabilitasi dan Rekonstruksi Pasar Raya Padang Ira Ariesta

Resolusi Konflik Berbasis Adat; Studi Resolusi Konflik Harta Pusaka Tinggi di Nagari Gantuang Ciri, Kab. Solok, Sumatera Barat

Yuhelna

Nelayan Vs Rentenir; Studi Ketergantungan Nelayan terhadap Rentenir pada Masyarakat Pesisir Delmira Syafrini 


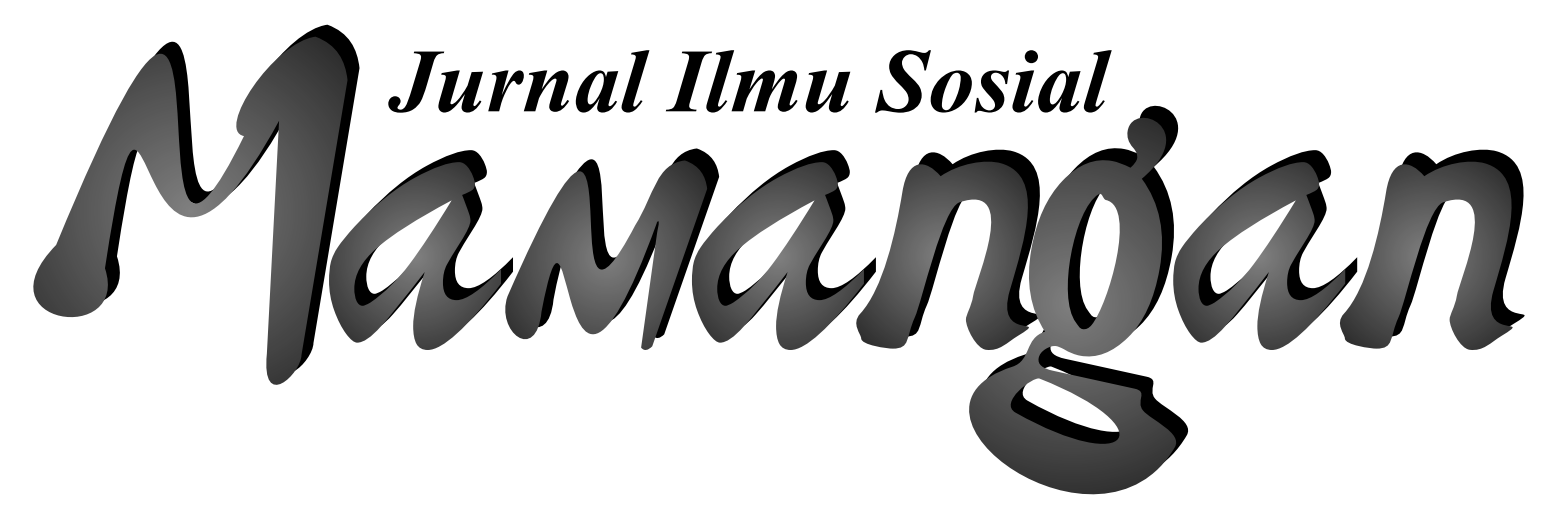




\section{Mitra Bestari}

Prof. Dr. Afrizal, MA. (FISIP, Unand Padang)

Prof. Dr. Badaruddin, M. Si. (FISIP, USU Medan)

Dr. A. Latief Wiyata, M. Si. (Universitas Jember, Jember)

Dr. Fikarwin Zuska, M. Si. (FISIP, USU Medan)

Nurus Shalihin, M. Si., Ph.D. (Fak. Ushuluddin IAIN Imam Bonjol Padang)

Dr. Semiarto A. Purwanto, M. Si. (FISIP, UI Jakarta)

Dr. Wahyu Wibowo, M. Si. (Universitas Nasional, Jakarta)

\section{Dewan Redaksi}

Dr. Zusmelia, M. Si.

Dr. Maihasni, M. Si.

Firdaus, S. Sos., M. Si.

\section{Pemimpin Redaksi/Editor}

Firdaus, S. Sos., M. Si.

\section{Anggota Redaksi}

Dian Kurnia Anggreta, S. Sos., M. Si.

Rinel Fitlayeni, S. Sos., MA.

Rio Tutri, M. Si

Sri Rahayu, M. Pd

Surya Prahara, SH,. MH.

Yuhelna, MA.

ISSN: 2301-8496

viii +81 halaman, $21 \times 29 \mathrm{~cm}$

\section{Alamat Redaksi:}

Laboratorium Program Studi Pendidikan Sosiologi, STKIP PGRI Sumbar Kampus STKIP PGRI, Jl. Gunung Pangilun, Padang, Sumatera Barat

Email: redaksimamangan@yahoo.com \& daus_gila@yahoo.com

\section{Penerbit:}

Laboratorium Program Studi Pendidikan Sosiologi, STKIP PGRI Sumbar

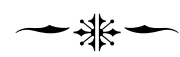




\section{PENGANTAR REDAKSI}

K onflik dalam masyarakat merupakan keniscayaan. Ia akan terus menjadi bagian dalam dinamika kemasyarakatan dan mengejawantah dalam berbagai bentuk yang secara garis bersar dikategorikan sebagai bentuk laten dan bentuk manifest. Pola dan bentuk konflik juga terus mengalami perkembangan sesuai dengan tingkat perkembangan masyarakat dimana konflik tersebut ada. Pola dan bentuk itu, mulai dari yang sederhana hingga yang paling 'canggih' dan bahkan disengaja ada untuk kepentingan tertentu oleh kelompok tertentu.

Meskipun para penganut fungsionalisme meganggap bahwa konflik dalam kehidupan sosial adalah abnormal (Johnson, 1994:161), namun konflik di lain kesempatan merupakan fakta sosial yang bisa fungsional bagi struktur tertentu selama ia dikelola dengan baik. Maka konflik kemudian di beberapa kesempatan juga dibutuhkan untuk kepentingan-kepentingan tertentu. Sehingga dengan demikian, adakalanya konflik mengikuti polanya sendiri dan adakalanya seirama dengan perkembangan masyarakat.

Menyadari bahwa perkembangan masyarakat terus melaju ke bentuk yang lebih kompleks, dan asumsi bahwa konflik juga akan kompleks sesuai dengan perkembangan kompleksitas masyarakat, Mamangan Edisi II yang ada di tangan pembaca ini mengambil konflik sebagai tema umum. Dalam edisi ini konflik dilihat oleh penulis dalam berbagai dimensi melalui berbagai pendekatan, baik secara teoritis maupun empiris melalui studi lapangan. Beberapa pakar di bisangnya telah menyumbang dalam dalam edisi kedua ini.

Tulisan pertama disumbangkan oleh Prof. Robert Lawang yang mendiskusikan konsep eksklusi sosial dalam konteks sosial, ekonomi dan politik. Tiga ranah ini menurut Lawang dikuasai arus utama (main stream) yang tidak mudah dimasuki oleh kelompok sosial tertentu dalam masyarakat paling bawah (underclass), sehingga mereka mengalami deprivasi. Selain itu, Lawang juga menyebut adanya perbedaan pandangan dan cara menjelaskan gejala sosial yang terkait eksklusi sosial. Meskipun konsep eksklusi sosial adalah konsep Barat, namun di Indonesia menurut Lawang, eksklusi sosial terjadi dalam berbagai struktur sosial masyarakat, baik di perkotaan maupun di pedesaan. 
Tulisan kedua disumbangkan oleh Noer Fauzi Rachman dan Dian Yanuardy yang mengupas secara kritis MP3EI. Dalam tulisannya, Fauzi dan Dian mempreteli skema MP3EI dan menyebutnya sebagai bagian dari upaya untuk memperdalam integrasi tanah air Indonesia ke dalam zona perdagangan bebas ASEAN dan Asia Timur. menurut mereka MP3EI pada pokoknya bertumpu pada upaya untuk melakukan reorganisasi ruang dalam rangka memperlancar interaksi dan aliran kapital, barang dan tenaga kerja untuk aktivitas produksi-konsumsi. Skema MP3EI dalam pola pemberian lisensi pada perusahaan untuk mengeksploitasi Sumber daya Alam menurutnya tidak jauh berbeda dengan kebijakan pemerintah kolonial Belanda sejak 1870, yang menempatkan Indonesia sebagai tempat produksi komoditas global.

Tulisan ketiga disumbangkan oleh Zayardam Zuber dan Zulqayim tentang rontoknya dominasi negara di Tambang Batubara Omblin, Sawahlunto. Zayardam dan Zulqayim dalam tulisannya mengemas sejarah beralihnya tambang di Kota Sawahlunto dari tangan perusahaan ke tangan rakyat yang selama puluhan tahun hanya menjadi penonton di arena tambang. Proses peralihan tersebut menurut Zayardan dan Zulqayim antara lain dilatari oleh penguasaan terhadap lahan di sekitar tambang yang dikuasi oleh dua kelompok, yaitu masyarakat adat dan pemerintah daerah. Selain itu, menurunnya aktivitas tambang PT. BA-UPO selaku BUMN yang kemudian menyerahkan pengurusan tambang kepada Pemda setempat juga menjadi bagian dari latar rontokya dominasi negara.

Tulisan keempat disumbangkan oleh Firdaus yang menguraikan protes korban bencana dalam proses rehabilitasi dan rekonstruksi di Pasar Raya Padang. Firdaus menyebutkan faktor penyebab munculnya protes adalah kebijakan pembangunan yang tidak partisipatif dan merugikan pedagang yang merupakan korban bencana. Kebijakan itu dibuat oleh pemerintah melalui mekanisme yang tidak sesuai dengan aturan yang ada. Protes yang dilakukan oleh korban bencana dilakukan dengan berbagai strategi, mulai dari strategi konfrontasi hingga negosiasi.

Tulisan kelima disumbangkan oleh Ira Ariesta yang mengulas peran perempuan dalam resolusi konflik Pasar Raya Padang. Ulasan Ira 'nyambung' dengan tulisan Firdaus sebelumnya. Jika Firdaus lebih menekankan pembahasan tentang penyebab dan strategi protes, maka Ira lebih menekankan pada resolusi konflik. Resolusi konflik yang dibahas Ira lebih fokus lagi pada peran perempuan. Menurut Ira, peran perempuan dalam proses resolusi konflik di Pasar Raya dilakukan oleh empat aktor utama, yaitu perempuan dari instansi pemerintah, perempuan aktivis LSM (PBHI Sumbar), perempuan aktivis mahasiswa dan perempuan pedagang. Keempat kelompok memainkan peran yang berbeda dalam resolusi konflik, mulai dari aksi massa hingga kegiatan advokasi terorganisir.

Tulisan keenam disumbangkan oleh Yuhelna yang membahas tentang mekanisme penyelesaian konflik harta pusaka tinggi secara adat di Minangkabau. Penyelesaian konflik harta pusaka tinggi di Minangkabau dilihat di nagari Gantuang Ciri. Resolusi konflik dilakukan pada 3 tingkatan. Tingkatan pertama resolusi konflik dilakukan di tingkat suku dengan melibatkan pangulu suku. Tingkat kedua resolusi konflik dilakukan pada tingkat yang lebih luas, yaitu pada institusi Tigo Niniak atau Ampek Niniak. Pada tingkat ini, resolusi konflik difasilitasi oleh niniak mamak masing-masing suku atau kaum yang berkonflik. Pada tingkat ketiga resolusi konflik dilakukan di lembaga adat Kerapatan Adat Nagari (KAN). Resolusi konflik pada tingkat ini difasilitasi oleh pengurus KAN yang merupakan perwakilan dari semua suku yang ada dalam nagari.

Tulisan terakhir, disumbangkan oleh Delmira Syafrini yang menganalisis ketergantungan nelayan dengan tengkulak di wilayah pesisir. Delmira melihat ketergantungan nelayan terhadap rentenir sebagai fenomena yang dilematis. Di satu sisi, nelayan mendapat kemudahan mengakses 
modal, di sisi lain nelayan dirugikan dengan suku bunga yang tinggi. Sementara, lembaga keuangan seperti Bank belum mampu menjadi katup penyelamat karena mekanisme rungguhan yang disyaratkan lembaga ini tidak terjangkau oleh nelayan. Di bagian akhir, Delmira menawarkan pemberdayaan sebagai solusi untuk memutus ketergantungan nelayan terhadap rentenir.

Demikianlah tulisan pada edisi ini, dan kepada para penyumbang tulisan pada edisi ini redaksi mengucapkan terima kasih atas karya intelektual dan buah pemikiran mereka, dan kepada para pembaca, redaksi mengucapkan selamat membaca. 



\section{DAFTAR ISI}

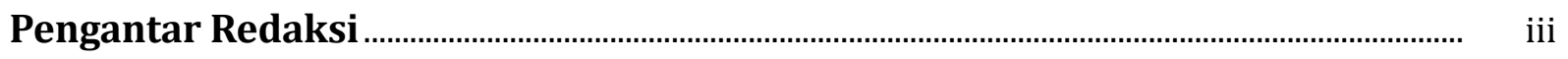

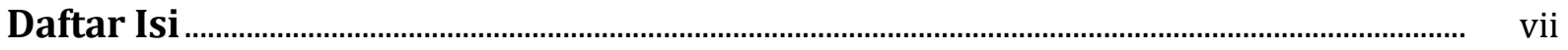

Beberapa Hipotesis Tentang Eksklusi Sosial di Indonesia

Robert M.Z. Lawang

Dapatkah Indonesia Bebas Dari Kutukan Kolonial?

Refleksi Kritis Atas MP3EI

Noer Fauzi Rachman \& Dian Yanuardy

Rontoknya Dominasi Negara di Tambang Batu Bara Ombilin Sawahlunto

Zaiyardam Zubir \& Zulqayyim

Protes Korban Bencana; Studi Konflik Penanggulangan Bencana di

Pasar Raya Padang

Firdaus

Peran Perempuan dalam Resolusi Konflik Rehabilitasi dan Rekonstruksi

Pasar Raya Padang

Ira Ariesta

Resolusi Konflik Berbasis Adat; Studi Resolusi Konflik Harta Pusaka Tinggi di Nagari Gantuang Ciri, Kab. Solok, Sumatera Barat

Yuhelna

Nelayan Vs Rentenir; Studi Ketergantungan Nelayan terhadap Rentenir pada Masyarakat Pesisir

Delmira Syafrini .

Profil Penulis. 



\title{
BEBERAPA HIPOTESIS TENTANG EKSKLUSI SOSIAL DI INDONESIA
}

\author{
Robert M.Z. Lawang \\ (Guru Besar Sosiologi, Fakultas Ilmu Sosial \& Ilmu Politik Universitas Indonesia) \\ 一非-
}

\begin{abstract}
Although the concept of social exclusion was developed in Western society context, the same phenomenon has been part of Indonesian societies today in somewhat different nature. It is true that social exclusion is related to both issues of poverty and underclass position as well, but approach to solve the problem has been starting from point related to one of them as accentuation. Regardless of performance achieved, Government of Indonesia has been considering the issues in the programs of concerned ministries.
\end{abstract}

Kata kunci : underclass, eksklusi sosial, kemiskinan.

\section{Pendahuluan}

Artikel ini disusun berdasarkan pengamatan dan keterlibatan langsung terkait isu-isu pengentasan kemiskinan yang dilakukan pemerintah dan swasta di Indonesia. Keterlibatan dalam diskusi evaluasi program pemerintah untuk mengentaskan kemiskinan, sangat berguna untuk membangun argumentasi tentang tiga isu yang saling terkait yakni kemiskinan - eksklusi sosial underclass. Beberapanya dapat disebut. Pertama, evaluasi terhadap pelaksanaan program PNPM MPd yang sedang dilakukan oleh Studi Perdesaan Universitas Gajah Mada (2013) khusus yang menyangkut tingkat perkembangan atau kondisi eksklusi sosial yang tidak sama untuk setiap desa di Indonesia. Kedua, evaluasi kritis yang dilakukan oleh Direktorat Jenderal Pemberdayaan Sosial dan Penanggulangan Kemiskinan Kementerian Sosial (2013), khusus yang terkait dengan usaha intervensi yang lebih berlandas pada inovasi pertanian, sehingga hanya dengan modernisasi ekologik pengentasan kemiskinan dapat menjadi lebih efektif dan berkelanjutan. Ketiga, evaluasi yang dilakukan Direktorat Jenderal Pemberdayaan Masyarakat Desa Kementeritan Dalam Negeri, khusus yang terkait dengan begitu banyaknya investasi di daerah perdesaan yang cenderung merusak lingkungan hidup masyarakat, sehingga sangat boleh jadi memperbesar lagi eksklusi sosial dan akhirnya berujung pada pemiskinan dan terperosok ke dalam underclass.

Yang dianggap cukup penting juga adalah pengalaman Sosiologi Perdesaan FISIP 
Universitas Indonesia menerapkan teknologi modern dalam sistem pertanian sawah irigasi di kabupaten Manggarai Timur, Flores NTT (2013-2014), sangat besar manfaatnya untuk mematangkan beberapa pokok pikiran yang antara lain terkait isu kemiskinan, eksklusi sosial dan underclass. Pertama, melalui penerapan paket Revolusi Hijau untuk jangka panjang (puluhan tahun), produktivitas lahan menurun drastis, sehingga pendapatan petani merosot tajam. Ditambah lagi dengan jumlah anak yang tidak terkontrol (5-7 anak), masalah putus sekolah yang serius, kebutuhan meningkat dan dengan besaran tanah hanya 0,15 ha, proses pemiskinan terus menghantui petani sawah di sana. Penggunaan pupuk urea dan TSP yang berlebihan sudah berdampak pada kerusakan tanah secara serius, dan hanya bisa menghasilkan 1 ton/ha. Kedua, perubahan dalam cara bertani mutlak diperlukan. Dari contoh awal sudah terbukti peningkatan produksi pertanian berlipat-lipat kali. Kesimpulannya, cara bertani organic merupakan satu-satunya solusi untuk mengentaskan kemiskinan, dan mengurangi eksklusi sosial serta terhindar dari masuk ke kelompok underclass yang lebih parah lagi.

Eksklusi sosial itu konsep Barat, yang belum tentu dapat diterapkan di Indonesia. Dari kajian pustaka yang ada (Karl Marx, A. Giddens 1973, C. Murray 1984, D. Gallie 1988, 1994, W.G. Runciman 1999, D. Byrne 1999, dll.) tidak terlalu jelas digambarkan hubungan antara beberapa konsep yang hendak dibahas di sini. Untuk mempertegasnya beberapa pertanyaan perlu dikemukakan : Pertama, apakah eksklusi sosial atau underclass merupakan penyebab kemiskinan? Kedua, apakah ada penyebab lain yang membuat berkembangnya eksklusi sosial sehingga ancaman pauperisasi semakin meningkat? Ketiga, baik eksklusi sosial maupun underclass harus dilihat dalam kerangka struktur sosial yang ada dalam suatu masyarakat. Terhadap ketiga pertanyaan itu ada beberapa jawaban singkat yang diberikan oleh para ahli sosiologi tentang eksklusi sosial. Dalam kajian ini, jawaban mereka perlu untuk memperkuat argumentasi tentang masalah eksklusi sosial, kemiskinan dan underclass di Indonesia.

1. Karl Marx menyebut underclass dengan istilah lumpenproletariat. Kelompok ini berada dalam kondisi miskin sedemikian rupa, sehingga hampir tidak dapat menyelamatkan dirinya sendiri. Malah mereka ini tidak mampu mengembangkan kesadaran kelas (class consciousness) dan karena itu tidak mungkin muncul suatu gerakan sosial atau tindakan kolektif untuk membebaskan dirinya dari cengkraman kapitalis. Kesimpulannya : kemiskinan dan underclass merupakan penyebab eksklusi sosial (dari dunia produksi, dan apalagi proses produksi dalam sistem kapitalis).

2. Analisis Giddens tentang eksklusi sosial di Inggris sedikit kontroversial. Dia membedakan dua macam pasaran tenaga kerja (labor market) yang primer dan sekunder. Yang primer itu penuh dengan kepastian dan imbalan pendapatan yang tinggi, sedangkan yang sekunder penuh dengan ketidakpastian dengan risiko tinggi. Kelompok kedua inilah yang mudah jatuh ke underclass. Inti pemikiran Giddens adalah struktur sosial yang tidak adil yang menyebabkan kelompok kedua ini kena eksklusi sosial dan terperosok ke dalam underclass. Pandangan Giddens ini kemudian dibantah oleh D. Gallie.

3. Murray juga tidak kalah kontroversialnya. Menurutnya kebijakan pemerintah tahun 1960-an tentang kesejahteraan sosial disalahgunakan terutama oleh warga kulit hitam, yang membuat membesarnya peluang orang miskin itu untuk tetap miskin, dan malah dapat terperosok ke dalam underclass. Begitu mereka masuk kategori underclass, eksklusi sosial terjadi melalui mekanisme sosial. Dengan cara yang sama dia melihat gejala yang serupa di di Inggris. Menurutnya, mereka yang termasuk underclass di Inggris 
sering menampilkan perilaku penyimpangan dan hilangnya semangat kerja, sehingga proses eksklusi sosial dapat menyebabkan mereka semakin jauh dari partisipasi kehidupan sosial, khususnya ekonomi.

4. Gallie menolak pandangan Giddens dan Murray tentang dampak struktur sosial terhadap eksklusi sosial dan underclass dan mengatakan sebaliknya. Ada kenyataan menunjukkan bahwa mereka yang berpendapatan rendah memiliki kepastian kerja, dan sebaliknya mereka yang memiliki pendapatan tinggi justru tidak memiliki kepastian kerja. Karena itu pembagian pasaran kerja primer dan sekunder yang dikemukakan Giddens itu tidak relevan. Dia juga mengeritik tentang analisis Murray tentang eksklusi sosial di Amerika dan Inggris dengan menunjukkan kenyataan bahwa ada orang kulit hitam di Amerika yang sama sekali tidak terkena proses eksklusi sosial. Begitu pula generalisasi perilaku menyimpang dan lemahnya semangat kerja pada keluarga kulit hitam dan Asia di Inggris tidak seluruhnya benar.

5. Runciman menghubungkan eksklusi sosial itu dengan sistem stratifikasi sosial berdassarkan ekonomi (struktur kelas) dengan membagi masyarakat Inggris menjadi 7 kelas sosial.

1) Upper class sebesar $0,1-0,2 \%$ dari populasi penduduk Inggris. Mereka ini menikmati gaji sangat tinggi karena peran mereka yang dalam penilaian Runciman 'irrelevant' to 'the institutional processes of production, distribution and exchange'. Mereka ini terdiri dari : (i) Pemilik alat produksi. (ii) Manajer senior dan (iii) Mereka yang menguasai pasar secara dominan.

2) Middle class menjadi tiga kelompok:

a. Upper middle class terdiri dari professional, pegawai negeri senior, dan manajer. Yang paling bawah dari kelompok ini adalah routine white-collar workers sebesar $<10 \%$ dari populasi.

b. Middle-middle class $20 \%$ dari populasi yang terdiri dari manajer media. c. Lower-middle class : pemilik property, dengan jumlah $20 \%$.

3) Working class sebesar $30 \%$ yang terdiri dari dua kelompok kelas:

a. Buruh trampil.

b. Tidak trampil (semi skilled).

4) Underclass adalah mereka yang ditanggung oleh Negara karena mereka tidak bisa berpartisipasi sama sekali dalam pasar tenaga kerja.

Dari hasil kajian awal tentang konsep eksklusi sosial di Negara Barat, kita dapat menyimpulkan beberapa hal. Pertama, kehidupan sosial ekonomi politik dikuasai arus utama (main stream) yang tidak mudah dimasukki oleh kelompok sosial tertentu dalam masyarakat paling bawah (underclass), sehingga mereka mengalami deprivasi dalam bidang sosial, ekonomi dan politik. Dalam bidang sosial hakhaknya diabaikan, sehingga menyulitkan dia untuk dapat memenuhi kebutuhan ekonominya. Dalam bidang ekonomi ada sistem yang secara langsung atau tidak langsung menghalangi kelompok sosial tertentu dalam masyarakat untuk mobilitas sehingga mereka terperosok ke lapis paling bawah (underclass). Dalam bidang politik nampaknya masih ada juga masalahmasalah diskriminasi yang terkait ras dan etnik terutama orang kulit hitam dan Asia, yang menyebabkan mereka terkucilkan dari peluang untuk berkembang. Kalau ketiga faktor itu bekerja sekaligus, dampaknya terhadap eksklusi sosial, kemiskinan dan underclass menjadi lebih besar lagi. Kedua, terdapat perbedaan pandangan dan cara menjelaskan gejala sosial yang terkait eksklusi sosial itu. Yang satu menganggap bahwa kebijakan sosial di Amerika Serikat sudah mendorong berkembangnya eksklusi sosial di kalangan warga kulit hitam, yang lain mengatakan justru sebaliknya. Begitu pula di Inggris tentang eksklusi sosial yang dihadapi oleh warga kulit hitam dan perempuan yang bekerja dan yang sementara yang lain menyimpulkan lain. Intinya, 
konsep ini masih longgar, dan perlu pemantapan substantif tentang apa sesungguhnya yang dimaksudkan dengan eksklusi sosial itu.

Dengan latarbelakang itu, ada beberapa pokok pikiran hipotetik yang hendak didiskusikan di sini. Pertama, struktur sosial dan eksklusi sosial itu dalam konteks masyarakat Indonesia dan Kedua, beberapa hipotesis yang perlu dikembangkan lebih lanjut.

\section{Eksklusi sosial Dalam Konteks Struktur Sosial}

Eksklusi sosial tidak terjadi dalam ruang hampa. Struktur sosial politik ekonomi ikut berperan dalam munculnya eksklusi sosial dan underclass. Indonesia tidak luput dari pengaruh itu. Beberapa pokok pikiran tentang struktur sosial Indonesia dapat dilihat sebagai berikut.

1. Konsep eksklusi sosial yang dibahas para ahli Barat dalam konteks masyarakat industri modern, dengan kondisi ekonomi yang maju dan penduduknya didominasi orang kulit putih, dan tradisi kristen yang panjang. Hasilnya antara lain eksklusi sosial perempuan, orang miskin, orang kulit hitam/bewarna. Belajar dari pembahasan itu, eksklusi sosial dalam konteks masyarakat Indonesia juga didasarkan pada asumsi tentang struktur sosial dimana eksklusi sosial itu terjadi.

2. Struktur sosial Indonesia terdiri dari komunitas-komunitas sebagai komponen strukturalnya. Pengertian dasar komunitas menunjuk pada satuan permukiman penduduk dengan batas-batas yang jelas dan sejarah terjadinya komunitas itu. Beberapa komponen struktural yang utama perlu dikemukakan di sini :

1) Komunitas perkotaan dengan kecenderungan struktur sosial sebagai berikut :

a. Penduduk bersifat heterogen menurut agama, etnik. Karena pola permukiman di Indonesia untuk beberapa kasus didominasi oleh agama dan etnik tertentu, maka dalam heterogenitas itu ada mayoritas dan minoritas dalam komposisi penduduknya. Dalam masyarakat perkotaan dengan struktur sosial seperti ini hipotesis tentang kelompok minoritas yang kena eksklusi sosial adalah mungkin. Pertanyaan berikutnya adalah apakah kelompok minortas itu juga otomatis miskin? Kecenderungannya, ada sukubangsa tertentu yang memiliki kemampuan ekonomik yang sangat tinggi, sehingga dimanapun dia berada, atau dalam struktur sosial apapun dia hidup, dia bertahan dan cenderung menjadi kaya. Contoh orang Cina, orang Padang di perantauan (minoritas), orang Batak, Bugis dan Jawa. Kesimpulan sementara (hipotetik) : minoritas yang berada di perantauan memiliki daya juang tinggi sehingga mereka tidak selamanya jatuh miskin, dan underclass. Kelompok transmigran masuk dalam kategori ini.

b. Sehubungan dengan kecenderungan hipotetik sebelumnya muncul pertanyaan : apakah eksklusi sosial itu dapat diterapkan untuk kelompok mayoritas? Untuk beberapa kasus memang demikian kecenderungannya. Transmigran asal Jawa dan Bali, termasuk orang Cina, dalam waktu relatif singkat dapat menguasai perekonomian dan seringkali juga perpolitikan lokal, sehingga mayoritas penduduk asli lama kelamaan terpinggirkan dari kegiatan ekonomi. eksklusi sosial dalam konteks ini sangat mungkin dan diikuti proses pemiskinan dan underclass. 
c. Pola permukiman perkotaan seringkali segregatif secara ekonomi. Orang kaya menumpuk di permukiman elit, sementara orang miskin menumpuk di permukiman kumuh. Dengan struktur komunitas seperti ini, ada kecenderungan eksklusi sosial dapat terjadi, tidak saja karena masalah struktur sosial yang tidak adil, melainkanjugakarena berkembangnya kebudayaan kemiskinan serta perilaku menyimpang.

2) Komunitas perdesaan yang sekarang ini berkembang di Indonesia memiliki kecenderungan berikut.

a. Semakin dekat dengan kota semakin terbuka kemungkinan berkembangnya heterogenitas perkotaan. Hipotesis yang berlaku untuk komunitas perkotaan, dapatterjadi pada kelompok seperti ini. eksklusi sosial yang terjadi adalah hilangnya peluang ekonomi karena mereka cenderung menjual tanahnya kepada orang kota, sehingga lama kelamaan mereka menjadi miskin dan masuk dalam kategori underclass.

b. Sebaliknya, semakin jauh desa itu dari kota, semakin homogen masyarakatnya dan semakin kecil peluang terjadinya eksklusi sosial.

3. Struktur sosial Indonesia juga terdiri dari pulau-pulau dengan tingkat perkembangan sosial ekonomi politik yang berbeda-beda. Dalam konteks ini ada kecenderungan terjadinya eksklusi sosial sehingga beberapa komunitas, etnik dan agama yang berada di pulau-pulau terpencil yang jauh dari ibukota negara, provinsi atau kabupaten.

4. Struktur sosial Indonesia juga terdiri dari bermacam-macam agama yang oleh kebanyakan orang Indonesia menjadi bagian penting dari identitas dirinya. Ada beberapa hipotesis tentang eksklusi sosial yang berkembang dalam struktur sosial seperti ini :
1) Secara umum dapat dikatakan bahwa penganut agama lokal (asli) mendapat eksklusi sosial dari penganut agama dari luar (Islam, Kristen Protestan, Katolik, Budha, Hindu, Kongfuchu).

2) Mereka yang tidak beragama (Komunis) juga mendapat eksklusi sosial dari penganut agama-agama besar (dari luar).

3) Ada sekte (kelompok agama) tertentu dalam agama Islam, Kristen yang cenderung mendapat eksklusi sosial.

5. Sudah lama Struktur sosial Indonesia terdiri dari partai - partai politik. Ada kecenderungan eksklusi sosial terjadi pada konstituen yang terabaikan dalam pengembangan kebijakan pemerintah (daerah kabupaten/ kota, provinsi) karena mereka tidak berpihak pada penguasa dalam pemilihan umum.

6. Struktur sosial Indonesia juga terdiri dari kelas sosial yang pada lapis paling bawahnya ada orang - orang sangat miskin (underclass), atau kalau di Indonesia disebut dengan istilah gepeng (gelandangan-pengemis) yang sangat rentan terhadap masalah sosial ekonomi politik. Secara sosial mereka dikucilkan, secara ekonomik mereka tidak dibutuhkan dalam pasaran tenaga kerja, dan secara politik mereka hanya perlu suaranya pada waktu pemilu. Proses ekslusi sosial terhadap mereka ini belum berhasil dihentikan.

\section{Beberapa Hipotesis Sebagai Kesimpulan}

Hipotesis berikut ini disusun berdasarkan peluang mereka yang termasuk dalam underclass dalam Struktur sosial Indonesia yang sudah dikemukakan sebelumnya.

1. Yang dissebut underclass adalah fakir miskin (miskin sekali) seperti yang dilaporan Badan Pusat Statistik (BPS) dalam Survey Sosial Ekonomi Nasional. Program pengentasan kemiskinan seperti yang dilakukan oleh Kementerian Sosial mengikuti pola ini. 
Kerangka hipotetiknya : underclass/ kemiskinan menyebabkan eksklusi sosial. Sebagian dari program PNPM MPd mengikuti pola ini.

2. Yang disebut eksklusi sosial di Indonesia bisa menunjuk pada beberapa satuan sosial seperti : fakir miskin, perempuan, orang lanjut usia, orang hidup di daerah terpencil, terkebelakang, penyandang stigma tertentu (komunis, narkoba, HIV Aids dll.). Mereka ini tidak dapat berpartisipasi dalam kegiatan ekonomi sosial politik arus utama. Beberapa institusi yang berurusan dengan masalah eksklusi sosial antara lain Kementerian Negara Urusan Perempuan, Kementerian Sosial, Kementerian Dalam Negeri, Kementerian Kesehatan (yang terakhir usaha untuk membagi kondom gratis : masih kontroversial), Kementerian Transmigrasi, Kementerian Pembangunan Daerah Tertinggal dan mungkin Kementerian Pertanian. Kerangka hipotetiknya: eksklusi sosial menyebabkan kemiskinan dan underclass.

3. Kemiskinan di Indonesia itu sangat rumit. Pertambahan penduduk di kalangan penduduk miskin yang tidak terkontrol di daerah perdesaan ikut menambah permasalahan pengatasannya. Potensi alam perdesaan yang sudah mulai rusak karena macammacam investasi yang tidak memperhatikan pelestarian lingkungan membuat semakin sulit pengentasan kemiskinan itu terlaksana. Kerangka hipotetiknya : eksklusi sosial daerah perdesaan sudah bersifat struktural, sehingga mempersulit underclass bisa keluar dan sebaliknya orang akan mudah terperosok ke dalamnya.

4. Usaha kaum buruh yang berhasil menaikkan Upah Minimum Regional (UMR) merupakan bukti munculnya kekuatan dari sebagian underclass untuk meningkatkan kesejahteraannya. Peraturan Menteri Tenaga Kerja No. 05/Men/1989 tanggal 29 Mei
1989 tentang Upah Minimum, adalah salah satu kebijakan Pemerintah yang memihak pada underclass. Kerangka hipotetiknya : pengembangan kebijakan yang memihak pada mereka yang kena eksklusi sosial, underclass dan kemiskinan.

\section{Daftar Pustaka}

BPS. Data dan Informasi Kemiskinan Kabupaten/ Kota 2010.

Haralombos M. and Holborn M, 2004. Sociology : Themes and Perspectives. Sixth Edition. HarperCollins Publisher.

Giddens, Anthony, 2006. Sociology. 5th Edition. Polity Press.

Brian, Barry,2002. "Sosial exclusion, sosial isolation and the distribution of income" in J. Hills et al. (eds) dalam Haralombos M. and Holborn M, hal. 236 - 289.

Burchardt, T. Le Grand J. and Pichaud, D, 2002. "Introduction" in J. Hills et al. (eds) (2002). Haralombos M. and Holborn M, hal. 236 289.

Hills, J, 2002. "Does a focus on sosial exclusion change the policy response?" in J. Hills et al. (eds) (2002). Haralombos M. and Holborn M, hal. 236 - 289.

Hills, J., Le Grand, J. and Piachaud, D. (eds), 2002. Understanding Sosial Exclusion. Oxford University Press, Oxford. Haralombos M. and Holborn M, hal. 236 - 289. 
